database consist over 13,000 accidents with outcome variables like frequency of accidents, fire related damages and nuisances, and fire deaths.

Results Evaluation of fire prevention programs is examined from two viewpoints. First, the results concern the requirements on information management. The relevant information concerning the costs, effects and risks for accurate utilisation of the method in strategic and operative conduct of fire services is pinpointed. Second, the study exposes the limitations and challenges in measuring the effectiveness of fire prevention. The variation in the key explanatory variables is used to identify their effects on outcome variables in order to study the causal effects of fire prevention.

Conclusions The Analysis is still a work in progress. The conclusions are expected to be completed by the end of 2015 .

\section{ASSESSING THE NUMBER OF FIRE FATALITIES IN A DEFINED POPULATION}

${ }^{1}$ Anders Jonsson, ${ }^{2}$ Anders Bergqvist, ${ }^{1}$ Ragnar Andersson. ${ }^{1}$ Karlstad University, Sweden; ${ }^{2}$ Swedish Fire Protection Association, Sweden

10.1136/injuryprev-2016-042156.109

Background Fire-related fatalities and injuries have become a growing governmental concern in Sweden, and a national vision zero strategy has been adopted stating that nobody should get killed or seriously injured from fires. There is considerable uncertainty, however, regarding the numbers of both deaths and injuries due to fires. Different national sources present different numbers, even on deaths, which obstructs reliable surveillance of the problem over time. We assume the situation is similar in other countries. This study seeks to assess the true number of firerelated deaths in Sweden by combining sources, and to verify the coverage of each individual source. By doing so, we also wish to demonstrate the possibilities of improved surveillance practices.

Methods Data from three national sources were collected and matched; a special database on fatal fires held by The Swedish Contingencies Agency (nationally responsible for fire prevention), a database on forensic medical examinations held by the National Board of Forensic Medicine and the cause of death register held by the Swedish National Board of Health and Welfare.

Results The results disclose considerable underreporting in the single sources. The national database on fatal fires, serving as the principal source for policymaking on fire-prevention matters, underestimates the true situation by $20 \%$. Its coverage of residential fires appears to be better than other fires.

Conclusions Systematic safety work and informed policy-making presuppose access to correct and reliable numbers. By combining several different sources, as suggested in this study, the national database on fatal fires is now considerably improved and includes regular matching with complementary sources.

\section{PROTECTING CHILDREN FROM FIRE AND BURN INJURIES IN PUNE THROUGH TRAINING AND AWARENESS}

Cinthia Pinto. Safe Kids Foundation, India

10.1136/injuryprev-2016-042156.110

Background Fire and burn injuries pose a serious risk to all especially to young children. Burn injuries often take a long time to heal and are either not entirely reversible or extremely expensive to treat in India. As per World Health Organisation report, around 265,000 deaths are caused by burns every year especially in low economic countries and globally nearly 96,000 children under the age of 20 were estimated to be fattlly injured as a result of fire realted burns in 2004. Fire incidents are on the rise even in Pune. In 2014, it is estimated that around 76,000 children sustained burn injuries in Pune alone and out of these around 2980 suffered third degree burns. The highest number of burn injuries occurred in the age group of $7-10$ years. $64 \%$ of the burn injuries happened at home.

Methods Safe Kids foundation India (SKFI) undertook extensive research conducted by IMRB international to understand preventable child injuries in Pune. Based on the findings SKFI has developed bilingual educational materials and safety messages. With the help of these, we will conduct training and create awareness among children and adults.

Objective Reduce fire, burn and scald injuries among children below 14 years of age in Pune by creating awareness that aim to change the behaviours.

Results The campaign will reach out to 325,000 students below 14 years of age and 175,000 parents in 3 years through community events and class room sessions. Educational and awareness efforts in schools \& communities and rising mindfulness among caregivers will result in protecting children from fire and burn injuries.

Conclusions The statistics are alarming, and there are global concerns as well. Change of behaviour on the part of parents and children will pave the way for a safe environment in Pune. SKFI is exploring opportunities to extend education and outreach efforts in other states in India such as Bangalore and Gurgaon.

\section{Burden of Injuries}

\section{Parallel Mon 1.7}

\section{FROM LOSS OF LIFE TO LOSS OF YEARS: SWEDISH INJURY FATALITIES FROM ANOTHER PERSPECTIVE}

'Linda Ryen, ${ }^{2}$ Mikael Svensson. ${ }^{1}$ Swedish Civil Contingencies Agency, Sweden; ${ }^{2}$ Sahlgrenska Academy, University of Gothenburg, Sweden

\subsection{6/injuryprev-2016-042156.111}

Background Traditionally, the burden of injury deaths is presented as the number of fatalities due to different injury types. In Sweden, the greatest number of accidental deaths is caused by falls followed by poisonings and road traffic accidents. There is however large differences among injury types when it comes to the age profile among those affected. By taking this into account, the distribution of the burden of injury among injury types will change dramatically.

Methods Using life expectancy tables and statistics on age, sex and type of injury for the victims, the plain number of fatalities due to injuries is converted to the sum of potential years of life lost due to injuries in Sweden for the time period 1972-2014.

Results Changing the perspective from counting the number of fatalities to summing the number of potential years of life lost according to life expectancy tables, dramatically changes which injury types cause the greatest burden on society.

The total number of life years lost due to injuries in 2014 amounts to about 108,000 of which almost half were lost due to accidents (unintentional injuries). Suicide account for about 25 
per cent of the injury fatalities but the share of life years lost amounts to 35 per cent, losing on average 32 years of life per fatality. For unintentional injuries, road traffic accidents historically have been the leading cause for loss of life years but since 2008 poisonings cause the highest loss. In 2014, also falls caused a higher number of life years lost than did road traffic accidents.

There are large differences in the average number of life years lost in different injury types. While the average fall fatality in 2014 caused a loss of 9 years, road traffic fatalities lost on average 32 years of life and poisoning fatalities on average 40 years. Conclusions Using potential years of life lost due to injuries as a complement to the number of deaths will change the picture of which types of accidents place the heaviest burden on society, allowing a more nuanced description of the burden of injury fatalities.

\section{COST OF CHILD AND ADOLESCENT INJURY IN THE UNITED STATES: BY AGE GROUP, CAUSE, AND PAYER}

Rebecca Spicer, Bruce Lawrence, Ted Miller. Pacific Institute for Research and Evaluation, Calverton, MD, USA

\subsection{6/injuryprev-2016-042156.112}

Background In 2012 in the United States, 13,454 children and adolescents died due to injury and another 9 million visited the emergency department or were hospitalised. However, incidence tells only part of the story. Costs are a better measure of burden by accounting for multiple injury consequences - death, severity, disability - in a single unit of measurement.

Methods We apply an established injury cost model to the Healthcare Cost and Utilisation Program (HCUP) sample-based emergency department and inpatient datasets and the U.S. Multiple Cause of Death file. In addition to medical and work loss costs, we take a societal perspective by including the estimated cost of quality of life and pain and suffering.

Results Injuries (fatal, hospitalised and ED-treated) to 0 through 19 year-olds in 2012 resulted in an estimated $\$ 92$ billion in medical and work loss costs and an additional $\$ 502$ billion in quality of life losses. Nonfatal injuries account for the majority $(83 \%)$ of these costs. Adolescents (ages 15-19) account for 29\% of the injuries but $37 \%$ of the costs. Falls and struck by/against injuries contribute to $51 \%$ of nonfatal injury costs and are the leading causes in all age groups. Assault-related injuries rank $5^{\text {th }}, 9^{\text {th }}$, and $4^{\text {th }}$ among 0-4, 10-14, and 15-19 year-olds, respectively. Selfharm ranks $9^{\text {th }}$ among 15-19 year-olds. Government costs are high with Medicaid paying for $43 \%$ of medical costs. Proportion paid by Medicaid is higher among 0-4 year-olds (54\%) and among assault (60\%), and unintentional firearm (62\%), bite and sting (56\%), and hot object/substance (55\%) injuries. The most severe and debilitating injuries will result in higher costs. Among nonfatal injuries, near-drownings are the most costly. Trafficrelated injuries are also among the most severe with pedestrian, motorcycle, and pedalcyclist injuries ranked \#2, \#4, and \#5 in mean injury cost.

Conclusions Cost data support priority-setting and intervention selection. Effectively addressing falls, struck by/against injuries, and assaults will reduce the burden of injury in the United States.

\section{ROAD TRAFFIC INJURY COST ESTIMATION BY WILLINGNESS TO PAY METHOD}

Elaheh Ainy, Hamid Soori. Safety Promotion and Injury Prevention Research Centre of Shahid Beheshti University of Medical Sciences

\subsection{6/injuryprev-2016-042156.113}

Background There are different methods for injury cost calculation. This study is the first ever one using the willingness (WTP) to pay method a middle-income country such as Iran in 2013 to calculate the cost of road traffic injuries (RTIs).

Methods In a Cost Analysis Method study on costs resulting from RTIs, 846 people per road user were randomly selected and investigated. The research questionnaire was prepared based on the standard for WTP method; Contingent value (CV), stated preference (SP), revealed preference (RP) model considering perceived risks. The collected data were analysed after their strict control. Final analysis of WTP was carried out using Weibull model and Bayesian method.

Results Mean age of the subjects was $33.4 \pm 9.9$ years old. Mean WTP was 87 among these road users. Statistical value of life for one death and one injury cases were estimated 19,713,584,906 IRR and 2,412,582,500 IRR respectively. In sum, 20408 death and 318,802 injury cases amounted to $1,171,450,232,238,648$ IRR equivalents to $39,048,341,074 \$$. Moreover in 2013, costs of RTIs constituted $6.46 \%$ of gross national income, which was $604,300,000,000$ \$. Findings obtained from Weibull model and Bayesian model showed that WTP had a significant relationship with age, gender, education, monthly income.

Conclusions Costs of traffic injuries were much higher than the global statistics. If policy making and resource allocation are made based on the scientific pieces of evidence, an enormous amount of capital can be saved through reducing death and injury rates. This method seems to be more precise method to traffic injury cost estimation than human capital method.

\section{PREVALENCE OF DISABILITY IN A DISTRICT OF BANGLADESH}

${ }^{1}$ Mohammad Moniruzzaman, ${ }^{1} \mathrm{M}$ Mostafa Zaman, ${ }^{2}$ Saidur Rahman Mashreky, ${ }^{2}$ AKM Fazlur Rahman. 'WHO Country Office for Bangladesh, Bangladesh; ${ }^{2}$ Centre for Injury Prevention and Research Bangladesh, Bangladesh

\subsection{6/injuryprev-2016-042156.114}

Background Data on disability among Bangladeshi people are suboptimal, extremely variable, methodologically inconsistent, and not precisely known. Therefore, we conducted a comprehensive survey on disability to determine prevalence and distribution of cause specific disability among residents of a district in Bangladesh.

Methods The survey was conducted in Manikganj, a typical district in Bangladesh, in 2009. Data were collected from 37,030 individuals of all ages. Samples were drawn out of 8,905 households from urban and rural areas proportionate to population size. Three sets of interviewer administered questionnaires were used separately for 0-1 years, 2-10 years, and 11 years and above age groups to collect data. For the age groups $0-1$ years 